This PDF is a selection from a published volume from the National Bureau of Economic Research

Volume Title: Producer Dynamics: New Evidence from Micro Data

Volume Author/Editor: Timothy Dunne, J. Bradford Jensen, and Mark J. Roberts, editors

Volume Publisher: University of Chicago Press

Volume ISBN: 978-0-226-17256-9

Volume URL: http://www.nber.org/books/dunn05-1

Conference Date: April 8-9, 2005

Publication Date: January 2009

Chapter Title: The Link between Human Capital, Mass Layoffs, and Firm Deaths

Chapter Author: John M. Abowd, Kevin L. McKinney, Lars Vilhuber

Chapter URL: http://www.nber.org/chapters/c0497

Chapter pages in book: (447 - 472) 


\title{
The Link between Human Capital, Mass Layoffs, and Firm Deaths
}

\author{
John M. Abowd, Kevin L. McKinney, and Lars Vilhuber
}

\subsection{Introduction}

The fairly sizable economics literature on displaced workers has typically concentrated on the effects of displacement on worker outcomes (Anderson and Meyer 1994; Bowlus and Vilhuber 2002; Fallick 1996; Jacobson, LaLonde, and Sullivan 1993b; Kletzer 1998; Kuhn and Sweetman 1998; Ruhm 1994; Schoeni and Dardia 1996; Stephens Jr. 2002), which is also an important subject in the field of Human Resource Management (Davis, Savage, and Stewart 2003; Grossman 2002). The analysis typically occurs at the level of a single plant or a sample of workers, for whom the displacement event itself is a given. A mostly separate and distinct literature considers the causes of firm or plant exit (death), and reductions in

John M. Abowd is the Edmund Ezra Day Professor of Industrial and Labor Relations at Cornell University and a research associate of the National Bureau of Economic Research. Kevin L. McKinney is an economist in the Longitudinal Employer-Household Dynamics program at the U.S. Census Bureau, and an administrator of the California Census Research Data Center. Lars Vilhuber is a senior research associate at the Cornell Institute for Social and Economic Research and a senior research associate in the Longitudinal EmployerHousehold Dynamics program at the U.S. Census Bureau.

The authors wish to thank Kristin Sandusky for providing us with the data extract from the Business Register. The authors acknowledge the substantial contributions of the staff and senior research fellows of the U.S. Census Bureau's Longitudinal Employer-Household Dynamics (LEHD) Program. This research is a part of the U.S. Census Bureau's Longitudinal Employer-Household Dynamics Program (LEHD), which is partially supported by the National Science Foundation Grant SES-9978093 to Cornell University (Cornell Institute for Social and Economic Research), the National Institute on Aging Grant R01 AG018854, and the Alfred P. Sloan Foundation. The computations for this research were done while at the Census Research Data Centers in Los Angeles, CA, and Ithaca, NY. This research is partially supported by the National Science Foundation Information Technologies Research Grant 
employment levels (downsizing) (Audretsch 1994; Bernard and Jensen 2002; Davis, Haltiwanger, and Schuh 1996; Dunne and Roberts 1990; Dunne, Roberts, and Samuelson 1988; Haltiwanger, Lane, and Spletzer 2007; McGuckin and Nguyen 1995, 2001). The usual explanatory variables for firm exits are size, age, innovations (Audretsch 1994; Dunne, Roberts, and Samuelson 1988), market structure, and efficiency (Foster, Haltiwanger, and Krizan 1998, 2002; Kletzer 1998). Few authors explicitly link the micro-level movement of workers with death and downsizing at either the plant or firm level. Notable exceptions are Abowd, Corbel, and Kramarz (1999), Lengermann and Vilhuber (2002), and Carneiro and Portugal (2003), which we will describe shortly.

There are many reasons employers use mass layoffs. They are not synonymous with the death of an establishment or firm. In our data, 55 percent of firms that have one displacement event between 1993 and 1996 are still alive in 1997. Conversely, if the decline in size is gradual, a firm death may not result in a displacement event.

Abowd, Corbel, and Kramarz (1999) have previously investigated worker and job flows for establishments with declining employment, and Lengermann and Vilhuber (2002) considered the distribution of worker skill levels in flows out of firms prior to displacement events. Both find that there are changes in such flows relative to alternate establishments (establishments with stable or increasing employment, or the same establishments in prior periods), but neither address the point specifically as a potential latent cause of displacement.

In the absence of a direct measure of worker skills, the literature has used wages as both a proxy for skills and as a cost component. Dunne and Roberts (1990), Bernard and Jensen (2002), and Carneiro and Portugal (2003) consider the determinants of wages and the effects on plant closures (Bernard and Jensen 2002; Dunne and Roberts 1990) or displacement events (Carneiro and Portugal 2003). Dunne and Roberts (1990) find that higher-paying firms have a significant, but economically small increase in the likelihood of plant failure. One postulated explanation for this small effect is that plants with higher wages also have a more productive work-

SES-0427889, which provides financial resources to the Census Research Data Centers. This document reports the results of research and analysis undertaken by U.S. Census Bureau staff. It has undergone a Census Bureau review more limited in scope than that given to official Census Bureau publications. The views expressed herein are attributable only to the authors and do not represent the views of the U.S. Census Bureau, its program sponsors, Cornell University, or data providers. Some or all of the data used in this chapter are confidential data from the LEHD Program. The U.S. Census Bureau supports external researchers' use of these data through the Research Data Centers (see www.ces.census.gov). For other questions regarding the data, please contact Jeremy S. Wu, Program Manager, U.S. Census Bureau, LEHD Program, Data Integration Division, Room 6H136C, 4600 Silver Hill Rd., Suitland, MD 20233, U.S.A., or visit http://lehd.did.census.gov 
force. In contrast to Dunne and Roberts (1990), Bernard and Jensen (2002) found that plants paying above-average wages have a lower likelihood of exiting. One plausible explanation for this result is that these firms use above-average human capital. Our analysis directly addresses this issue by deriving a measure of general (nonfirm-specific) human capital and using it instead of, or in addition to, wages.

Closest in spirit to our analysis is Carneiro and Portugal (2003), who estimate simultaneous plant failure and wage determination equations for Portugal. Their measures of human capital are the usual right-hand side variables in a Mincerian wage equation (education, age, tenure), but they do not include a measure of the physical capital of the firm. Furthermore, plant layoff is estimated as an event at the individual level. The distribution of human capital within the firm is not taken into account.

In this chapter, we correlate firm-level measures of human and physical capital (capital intensity), as well as measures of efficiency (sales per worker) with displacement events. We differ from the literature in our use of a measure of human capital, rather than a direct measure of wages, and we consider the effect of the distribution of human capital within a firm on both displacement and firm-death outcomes.

Based on methods first developed in Abowd, Lengermann, and McKinney (2002), we estimate a measure of human capital, based on observed and unobserved worker ability. Using this measure, we estimate firmspecific distributions, which allows us to consider the impact of differences in the use of human capital across firms on outcome variables. We identify displacements from quarterly worker flows, and merge data on firm performance and capital from Economic Censuses. Firms active in our data in 1992 are classified as survivors or exiters, depending on their activity in 1997. This set of companies is then cross-classified by whether or not they have experienced a single mass layoff, or multiple displacement events.

To anticipate our results, single displacement events occur substantially more often in firms that employ more workers in the lowest quartile of the human capital distribution. Firm closures occur substantially more often in firms that disproportionately employ workers in the lowest quartile of the human capital distribution and less often in firms that employ relatively more workers in the highest quartile of this distribution. Conditioning the firm closure analysis on the displacement event, our analysis suggests that firms that disproportionately employ workers in the highest quartile of the skill distribution are less likely to close, even given a displacement event, than are other firms that experience displacement events.

The chapter is organized as follows. Section 12.2 lays out the basic definitions of human capital and displacement as used throughout our chapter. Section 12.3 describes the data used, section 12.4 provides results, and section 12.5 concludes. 


\subsection{Definitions}

The definitions of economic activity, human capital, and mass layoff are obviously crucial for our analysis. In this section we consider each concept in turn, state our definition, and relate our measure to alternatives that have been used by others.

\subsubsection{Defining Economic Activity}

Economic activity of firms in our sample is defined by the observation of positive employment in the Longitudinal Employer-Household Dynamics (LEHD) Infrastructure files in 1992. Survivors are those firms that are still active, by the same definition, in 1997. Additional data are matched from the Economic Census in 1992 and 1997, when available. This universe is essentially the ES-202 establishments that were alive in 1992 (positive employment), which are the basis for the LEHD Infrastructure File known as the Employer Characteristics File (Abowd et al., chapter 5 in this volume). An alternative frame might have been either the Economic Census frame, in which case some establishments in-scope but missing from the LEHD Infrastructure Files would have missing human capital data.

\subsubsection{Defining Human Capital}

We provide a brief overview of our approach in this section. For a more complete discussion of the definition of the within-firm human capital distribution, and of human capital itself, see Abowd, Lengermann, and McKinney (2002). Assume human capital $H_{i t}$ has a market-return (average rental rate) $r_{t}$. The wage is $w_{i t}=r_{t} H_{i t}$, where $i$ indexes persons and $t$ indexes time. Individual firms might deviate from $r_{t}$, paying $r_{t} p_{j}$, with $E\left[p_{j}\right]=1$, where $j$ indexes employers. Assume that a person-specific component $\left(\theta_{i}\right)$ and a general experience component $\left(X_{i t} \beta\right)$ are important factors determining the accumulation of human capital. Then, taking logarithms, we have $\ln H_{i t}=\theta_{i}+X_{i t} \beta$. We thus obtain the following model of earnings

$$
\ln w_{i t}=\ln r_{t}+\psi_{j}+\theta_{i}+X_{i t} \beta
$$

where $\psi_{j}=\ln p_{j}$. Deviating $w_{i t}$ and $X_{i t}$ from the grand mean across individual and time periods produces the estimating equation: ${ }^{1}$

$$
\ln w_{i t}=\theta_{i}+\psi_{j}+X_{i t} \beta+\varepsilon_{i j t}
$$

where $\theta_{i}$ is the person effect, $\psi_{j}$ is the firm effect, and $X_{i t}$ are time-varying person characteristics (such as experience), and $\varepsilon_{i j t}$ is the statistical residual.

To compute a measure of a person's human capital, we combine the es-

1. See Abowd, Creecy, and Kramarz (2002) for details. We have not changed the notation for the wage rate or the experience variables since subtracting a constant is just a technique for imposing one of the identification requirements for the estimation of both person and firm effects. 
timated person effect $\hat{\theta}_{i}$, the experience components (after restoring the mean of $X_{i t}$ ) of person characteristics $X_{i t} \hat{\beta}$, and the reference constant $\delta$ to compute

$$
\hat{h}_{i t}=\hat{\theta}_{i}+X_{i t} \hat{\beta}+\delta .
$$

Because the estimated person effect $\left(\hat{\theta}_{i}\right)$ absorbs all the usual time-invariant explanatory factors (such as sex, education, and age at first entry) and also absorbs all unobserved (by the analyst) time-invariant factors, such as innate ability, $h_{i t}$ corresponds to the concept of general human capital.

Once $\hat{h}_{i t}$ is computed, we estimate firm-level kernel density estimates of its distribution, yielding a firm-specific distribution of human capital $g_{j t}\left(\hat{h}_{i t}\right)$, and

$$
G_{j t}(\hat{h})=\int_{\underline{H}}^{\hat{h}} g_{j t}(x) d x
$$

where $\underline{H}$ and $\bar{H}$ define the support of $\hat{h}$. To obtain discrete measures, we partition $[\underline{H}, \bar{H}]$ into 4 subsets, and calculate the population quartiles $q_{k}^{*}$ implicitly defined by

$$
G\left(q_{k}^{*}\right)=\int_{\underline{H}}^{q_{k}^{*}} g(x) d x=k \cdot 0.25
$$

where $k=1,2,3,4$. For each firm, we then calculate the proportion of workers who have human capital within the ranges defined by the overall population quartile boundaries $q_{k}^{*}$ for for $k=1,2,3,4$.

$$
\Gamma_{j t}(k)=G_{j t}\left(q_{k}^{*}\right)-G_{j t}\left(q_{k-1}^{*}\right) .
$$

These employer-level measures summarize the complete distribution of workers' human capital at the establishment. Similar measures $\Gamma(k)$ are computed for the experience $\left(X_{i t} \hat{\beta}\right)$ and estimated person effect $\left(\hat{\theta}_{i}\right)$ distributions within the firm.

While our firm-level human capital measure is obviously related to wage rates, it is important to note that its distribution is different from the distribution of wage rates at the establishment at a point in time. By removing the firm effects and the idiosyncratic residuals from the labor market distribution of $h$, from which we measure the reference quartile points, between-firm differences in compensation policy, which might be due to specific human capital or other active compensation policies, are removed from the human capital measure. Generally, such effects are included in within-firm wage dispersion measures used by other authors (e.g., Gibbons et al. 2005; Lluis 2005).

\subsubsection{Defining Mass Layoffs}

In keeping with the previous literature on the impact on workers of mass layoffs (Bowlus and Vilhuber 2002; Jacobson, La Londe, and Sullivan 1993a, 1993b; Schoeni and Dardia 1996), we define a mass layoff in period 
$t$ as a 30 percent single-period drop in employment from firm $j$ 's maximum employment level over the observed time period:

$$
D_{j t}=1 \text { if } \frac{S_{j t}}{B_{j}^{\max }}>0.3
$$

where $B_{j}^{\max }=\max _{t} B_{j q}$ over the time period that firm $j$ is in the sample with positive employment. Firm $j$ 's beginning-of-quarter employment, $B_{j t}$, is a point-in-time measure derived by summing over workers employed at the firm in both period $t-1$ and $t$. Worker separations from firm $j$ are $S_{j t}$ (i.e., workers that worked for the firm in period $t$ but are no longer observed on the payroll in period $t+1$ ). Note that in our analysis, all firm deaths are classified as displacements. However, they may not involve mass layoffs. On the other hand, among survivors, some firms experienced mass layoffs, and some did not.

Due to some limitations of the administrative data used for this chapter, a naïve use of the mass layoff equation (7) will overstate mass layoffs by some margin. ${ }^{2}$ In order to reduce the impact of spurious events, we take particular care to exclude firms that either change identity or who continue to operate, yet fail to file a firm report.

The firm identifier underlying all of our analysis is a state-specific Unemployment Insurance account number, whose primary purpose is to facilitate the administration of a state's unemployment insurance system. These account numbers can and do change for reasons such as a simple change in legal form or merger. In our analysis, the separation of a worker from a firm is identified by a change in the firm identifier on that worker's wage records. If a firm changes account numbers, but makes no other changes, the worker would seem to have left the original firm, when in fact his employment status remains unchanged. Thus, a simple change in account numbers would lead to the observation of a mass layoff at the firm associated with the original account number. ${ }^{3}$

To identify spurious employer birth and death events, we track large worker movements between firms. Benedetto et al. (2007) provide an analysis for one particular state of such an exercise using LEHD data. For this chapter, if we observe 80 percent of a firm (the predecessor) moving to a single successor, then we eliminate the displacement event. The assumption is that such a movement is associated not with a layoff, but a reorganization, a takeover, or some similar event. Similarly, if we observe that 80 percent of a successor's employment stems from the same predecessor, then a displacement event is also eliminated.

2. Abowd and Kramarz (1999) and Vilhuber (forthcoming) provides an overview over several approaches to correcting the weaknesses of administrative data sets. Abowd and Vilhuber (2005) discuss one particular weakness, a corrective measure, and the impact it has on aggregate statistics, including on measures similar to the mass layoffs of interest in our chapter.

3. Other authors working with administrative data have also addressed this problem in similar ways (see Anderson and Meyer 1994 and Jacobson, LaLonde, and Sullivan 1993a). 
A second, not uncommon, event observed in administrative data is the failure of a firm to file a timely report. In general, such an absence will trigger a follow-up by the state administration, since tax payments are linked to the report. However, for multiple reasons, the corrected or late filing by the firm may not get entered into the database transmitted to LEHD. The result is a hole in the firm's activity.

Holes, however, are precisely what would also be observed if a firm laid off its entire workforce for more than a quarter - a mass layoff - and hired them or other workers back later. The approach we have taken to distinguish data-related holes from true layoffs is the following. Consider the different employment path of an individual $i$ at some firm $j$. Define time $\lambda$ to be the elapsed fraction of a quarter $t, \lambda \in[0,1]$. If the individual left the firm at some point $0<\lambda<1$, then observed earnings $E_{i t}$ will be $E_{i t}=\lambda e_{i t}$, where $e_{i t}$ is the quarter $t$ wage rate for individual $i$. If the individual worked for the entire quarter, then observed earnings will be $E_{i t}=e_{i t}$. We do not observe $\lambda$, but assume that the quarterly wage rate is constant $\left(e_{i t}=e_{i 0}\right)$, where 0 is some baseline period, typically a prior quarter within the same job history. Compute $\Delta E_{i}=E_{i t} / E_{i 0}$. Then $\Delta E_{i}=1$ implies $\lambda=1$. On the other hand, if $\Delta E_{i}<1$, then the worker left at some time $\lambda<1$.

Now compute the average, $\Delta E_{t}^{j}$ for all workers within a firm $j$ at date $t$; that is,

$$
\Delta E_{t}^{j}=\left(\sum_{i \in J(i, t)} \Delta E_{i T}\right) /\left(\sum_{i} 1[j=J(i, t)]\right)
$$

where $J(i, t)$ is a function giving the identity, $j$, of the firm employing $i$ at date $t$ (Abowd, Kramarz, and Margolis 1999). Now consider if $\Delta E_{t}^{j}=1$ (i.e., the average ratio of earnings is equal to unity). It is unlikely that all workers leave the firm at the same time, except, of course, if a mass layoff occurs. It is, however, even more unlikely, though not impossible, that that mass layoff occurs on the last day of the quarter, which is what $\Delta E_{t}^{j}=1 \mathrm{im}-$ plies. Suppose further that no employment is observed at firm $j$ in period $t+1$, but positive and large employment is observed in period $t+2$, with $\Delta E_{t+2}^{j}=1$ as well. This hole is very unlikely to occur under normal circumstances - it implies that all workers left the firm at the end of quarter $t$, and all workers started working again on the first day of quarter $t+2$. It $i s$, however, the data pattern that is expected when a firm neglects to file all worker records for quarter $t+1$. We consider mass layoff events that are synchronous with such holes to be data artifacts, not true layoff events, and we filter them out.

\subsection{Data}

To estimate the impact of displacement, we use data from three states, California, Illinois, and Maryland, covering the time period 1990 to 2003. The data used to estimate the human capital model and to identify firm 
displacement events are derived from the LEHD Infrastructure Files. The LEHD Infrastructure Files provide a worker's quarterly earnings history, basic demographic information, and, most importantly, identify a person's employer. The fact that we know the history of the firm and the employees at that firm over time allows us to estimate displacement events as well as provide a richer characterization of the employees at the firm.

The human capital estimates (equation 2) are calculated using data from the LEHD infrastructure files for the twenty-two states available as of November 30, 2004. Once the estimates have been produced, we select workers employed in California, Maryland, and Illinois during 1992 and/or 1997. In order to get a snapshot or point-in-time measure of the human capital at the firm, we further restrict our analysis to workers employed at the end of quarter 1 (a date that roughly coincides with the collection of Economic Census data). Finally, we only keep workers between the ages of 18 and 70, with earnings during the quarter of greater than $\$ 250.00$.

Additional information, such as a firm's sales and capital stock, is gathered from the 1992 and 1997 Economic Censuses. Capital stock is only available for the manufacturing sector. Sales variables are available only for a subset of firms. At the time we were preparing this version, the 2002 Economic Census was not available, although we expect to use these data in the future. Because of our desire to incorporate information from the Economic Censuses, we will only directly analyze individuals and firms during the period 1992 to 1997, even though the human capital estimates are calculated using data for the full time period.

Due to the dynamic nature of the U.S. economy it is difficult to differentiate normal flows of employment from displacements for smaller firms. For example, a firm with ten employees that has three workers leave during the quarter would be classified as having a displacement under our standard definition, even though three workers leaving a firm in the same quarter is not a particularly unusual event. In order to focus our analysis on large displacement events, we limit our sample to firms that average at least fifty workers across the entire time period.

The firm-level displacement database contains indicators for all displacement events that occur during three time periods: 1992, 1993 to 1996, and 1997. We select a sample of firms that were active during 1992. Firms still present in 1997 are survivors, otherwise firms are called exiters. This sample differs from Abowd, Lengermann, and McKinney (2002), where firms entering the sample between 1992 and 1997 were also included. We do not impose any restrictions on the incidence of displacement events during either 1992 or 1997, although the effect of this decision is worthy of further exploration. Firms are classified as to whether they experienced zero, one, or multiple displacement events in the years 1993 to 1996. Crossclassifying this grouping with exit status yields the six different types of firms we focus on in this chapter. 


\subsection{Analysis}

The incidence and magnitude of displacement events in our data are shown in table 12.1. About 70 percent of the nearly 50 thousand firms in our sample never experience a displacement event between 1993 and 1996. On the other hand, 15 percent experience multiple displacement events over the same period, with the remaining firms experiencing a single event over the period. These groups turn out to be analytically distinct. For most of our analysis we will concentrate on the comparison between firms experiencing zero and one displacement events. However, multiple-displacement firms are a group that remains of interest for this research. A more detailed characterization of the excluded multiple-displacement group can be found in the appendix.

About 18 percent of firms die between 1992 and 1997 and, in line with our intuition, firms experiencing a single displacement are much more likely to die, as shown by row two of table 12.2. In this respect, firms with multiple displacements are very similar to firms that experience no displacement at all, suggesting that most firms with multiple displacements structure the firm with the expectation that a sequence of large demand shocks will occur. In general, firms with no displacements are bigger both in terms of their workforce as well as in terms of total sales and sales per worker (when available). In terms of their per-worker capital stock (available for manufacturing firms) firms with no displacement events and firms with multiple displacements are very similar. Single displacement firms have a lower capital intensity than either of the other two groups.

Turning to the distribution of human capital, firms with displacement events have an above-average fraction of their workforce in the lower skill $(\theta)$ and human capital $(h)$ distribution $\Gamma(1)$, at the expense of the upper tail of the distribution $\Gamma(4)$. In general, the human capital seems to be shifted further to the left the more displacement events a firm has.

Table 12.1

Displacement and survival among 1992 firms

\begin{tabular}{lcccc}
\hline & \multicolumn{3}{c}{ Displacement events } & \\
\cline { 2 - 4 } Firm type & 0 & 1 & Multiple & Total \\
\hline Exiters & 4,575 & 3,364 & 1,098 & 9,037 \\
& 50.63 & 37.22 & 12.15 & 18.65 \\
& 13.61 & 45.18 & 14.86 & \\
Survivors & 29,045 & 4,082 & 6,291 & 39,418 \\
& 73.68 & 10.36 & 15.96 & 81.35 \\
Total & 86.39 & 54.82 & 85.14 & \\
& 33,620 & 7,446 & 7,389 & 48,455 \\
& 69.38 & 15.37 & 15.25 & 100.00 \\
\hline
\end{tabular}




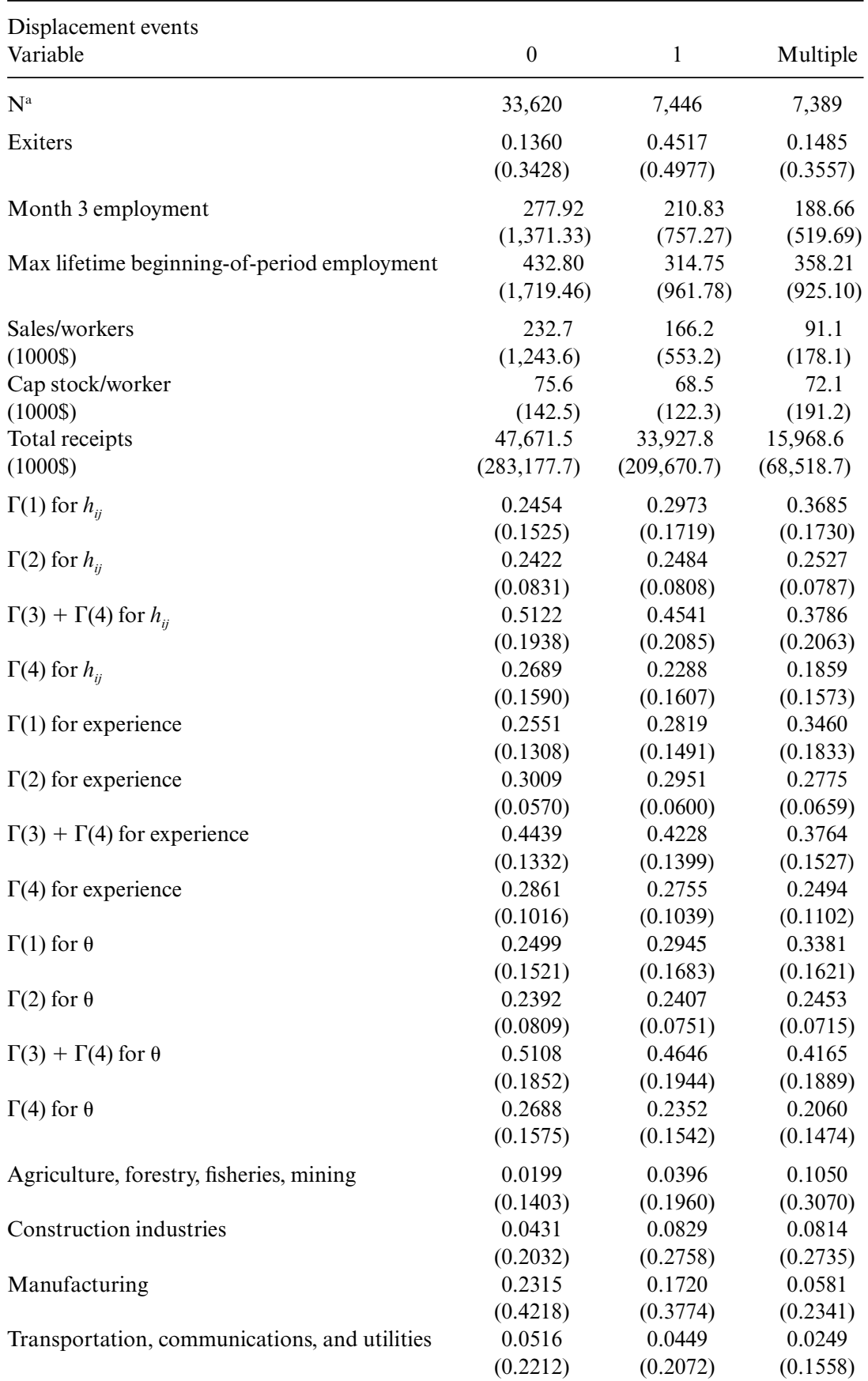


Table 12.2

(continued)

\begin{tabular}{lccc}
\hline $\begin{array}{l}\text { Displacement events } \\
\text { Variable }\end{array}$ & 0 & 1 & Multiple \\
\hline Wholesale trade & 0.1027 & 0.0710 & 0.0274 \\
& $(0.3036)$ & $(0.2569)$ & $(0.1634)$ \\
Retail trade & 0.1160 & 0.1817 & 0.2722 \\
& $(0.3202)$ & $(0.3856)$ & $(0.4451)$ \\
Finance, insurance, and real estate & 0.0839 & 0.0564 & 0.0179 \\
& $(0.2773)$ & $(0.2307)$ & $(0.1329)$ \\
Service industries & 0.3257 & 0.3349 & 0.3920 \\
& $(0.4686)$ & $(0.4720)$ & $(0.4882)$ \\
Public administration & 0.0251 & 0.0161 & 0.0205 \\
& $(0.1566)$ & $(0.1259)$ & $(0.1419)$ \\
\hline
\end{tabular}

aAll cells correspond to the number of observations in line 1, except for "Sales per worker" $(26,273 / 5,761 / 5,473)$, "Capital stock per worker" $(6,720 / 1,045 / 346)$, and "Total receipts" $(26,353 / 5,790 / 5,493)$.

While firms with multiple displacements differ in their observable characteristics from firms in other categories, they do not seem to die as often as firms with singe displacements (row two of table 12.2). In other words, they seem to be stable firms with highly volatile, possibly seasonal, workforce fluctuations (see also the discussion in the appendix). Although it is worthwhile to try to further disentangle the correlates of the highly volatile employment patterns, in the remainder of this chapter we will concentrate on firms with zero or one displacement event.

\subsubsection{The Probability of Displacement}

The summary data in table 12.2 suggest that firms with a single displacement event are more likely to die. They also have distinct observable characteristics prior to the displacement event. To disaggregate some of the possible causes of displacement events, we specify a univariate probit model:

$$
\operatorname{Pr}\left(D W_{j}=1 \mid Y_{j}\right)=\Phi\left(\beta Y_{j}\right)
$$

where $D W_{j}$ is equal to one when firm $j$ experienced a displacement event in the eligible period (in this chapter, between 1993 and 1997). We include in $Y_{j}$ measures of the firm's human and physical capital or capital intensity (if available), sales per worker (worker productivity), and indicators of firm structure (multi- or single-unit). Also, $Y_{j}$ includes industry level variables for firm $j$ 's primary SIC: the concentration index or unrestricted industry effects.

We estimate equation (8) for all firms active in 1992. Table 12.3 presents the results for the firm performance and human capital variables. Columns (1) through (6) report results for the sample of firms for which complete 


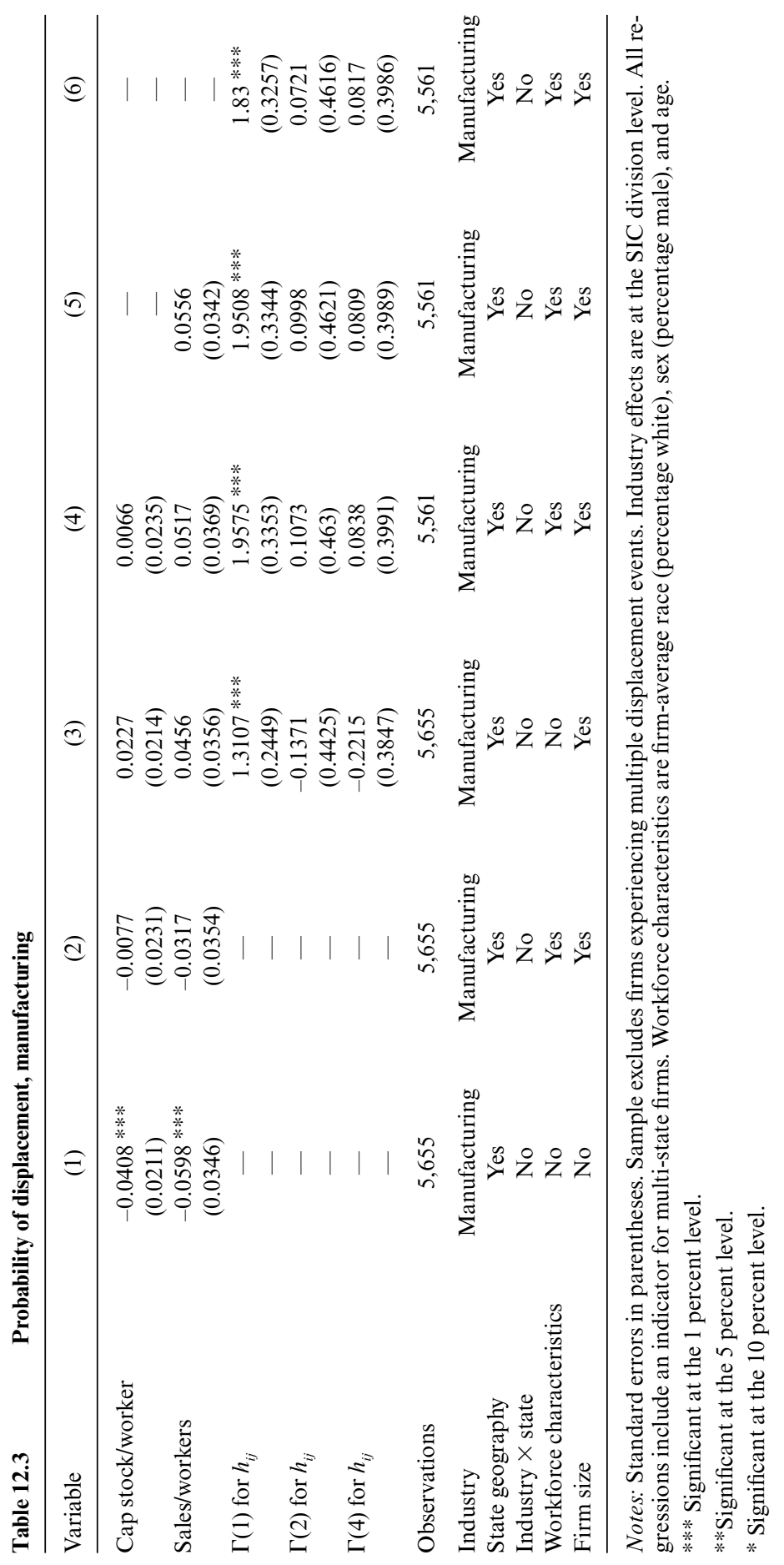


sales and assets information is available. This specification is similar to others in the literature (Bernard and Jensen 2002; Carneiro and Portugal 2003; Dunne and Roberts 1990) but is not representative of all firms in our sample.

Column (1) is a simple specification that correlates sales and assets per worker to the likelihood of a displacement, conditional on unrestricted industry and geography effects. Both firm performance variables are significant. However, in column (2), the addition of worker demographics reduces the effect of the firm performance variables, and neither is significant at conventional significance levels. Although not reported in the table, the estimated coefficients on worker characteristics suggest that firms with a predominantly male workforce, with more part-time workers, and with an older workforce are all more likely to have a displacement event. In column (3), we replace the observable workforce characteristics with $\Gamma(1), \Gamma(2)$, and $\Gamma(4)$. Note that the only significant variable is $\Gamma(1)$, a measure of how much of the workforce is in the lower tail of the skill distribution. A larger fraction of a firm's workforce being in the lower tail of the skill distribution in 1992 increases the likelihood of a displacement event in the next five years. This result remains robust to the introduction of observable workforce characteristics in column (4). Thus, it would seem that the distribution of human capital captures a significant amount of the productivity factors that affect the incidence of mass layoffs.

As noted previously, the sample of firms with complete sales and asset information is not representative of the full sample. Columns (5) and (6) test specifications that successively eliminate the sales and assets variables for the same sample as in columns (1) and (4). The impact on the coefficient on $\Gamma(1)$ is negligible.

In table 12.4, we widen the sample selection criteria in two ways. First, we expand the sample to include all firms that have available sales data but do not necessarily have available capital intensity data. The sample increases to 25,236 firms. The specification in columns (1) and (2) in table 12.4 corresponds to the one in columns (5) and (6) in table 12.3 estimated for the new sample. In the wider sample, sales per worker still has a significant impact on the incidence of displacement events. The effect of the lower tail of the human capital distribution is reduced, although still highly significant. Whether this result is due to greater homogeneity in the table 12.3 sample or some other factor remains to be explored. Dropping the sales variable in column (2) of table 12.4 increases the absolute value of the $\Gamma(4)$ coefficient, suggesting that in this sample, there is some correlation between sales per worker and the human capital intensity in the firm.

In order to control for local market effects, we fully interacted geography and industry effects, allowing industries in each state to have different effects. As the results in columns (3) and (4) illustrate, this has no meaningful impact on the results. 
Table 12.4

Probability of displacement, other industries

\begin{tabular}{lcccccc}
\hline Variable & $(1)$ & $(2)$ & $(3)$ & $(4)$ & $(5)$ & $(6)$ \\
\hline Cap stock/worker & - & - & - & - & - & - \\
Sales/workers & $-0.065^{* * *}$ & - & $-0.0609 * * *$ & - & - & - \\
& $(0.013)$ & - & $(0.013)$ & - & - & - \\
$\Gamma(1)$ for $h_{i j}$ & $1.1265^{* * *}$ & $1.2492^{* * *}$ & $1.149^{* * *}$ & $1.2665^{* * *}$ & $1.3658^{* * *}$ & $1.376^{* * *}$ \\
& $(0.1355)$ & $(0.1332)$ & $(0.1361)$ & $(0.1338)$ & $(0.0998)$ & $(0.1002)$ \\
$\Gamma(2)$ for $h_{i j}$ & -0.167 & -0.1716 & -0.1346 & -0.1361 & -0.2192 & -0.1994 \\
& $(0.2344)$ & $(0.2342)$ & $(0.2351)$ & $(0.235)$ & $(0.1746)$ & $(0.1754)$ \\
$\Gamma(4)$ for $h_{i j}$ & -0.2303 & $-0.35 * *$ & -0.2627 & $-0.3738^{* *}$ & -0.1302 & -0.1377 \\
& $(0.1729)$ & $(0.1713)$ & $(0.1739)$ & $(0.1722)$ & $(0.1252)$ & $(0.1258)$ \\
Observations & 25,236 & 25,236 & 25,236 & 25,236 & 41,066 & 41,066 \\
Industry & Yes & Yes & No & No & Yes & No \\
State geography & Yes & Yes & No & No & Yes & No \\
Industry $\times$ state & No & No & Yes & Yes & No & Yes \\
Workforce characteristics & Yes & Yes & Yes & Yes & Yes & Yes \\
Firm size & Yes & Yes & Yes & Yes & Yes & Yes \\
\hline
\end{tabular}

Notes: Standard errors in parentheses. Sample excludes firms experiencing multiple displacement events. Industry effects are at the SIC division level. All regressions include an indicator for multi-state firms. Workforce characteristics are firm-average race (percentage white), sex (percentage male), and age.

*** Significant at the 1 percent level.

** Significant at the 5 percent level.

* Significant at the 10 percent level.

For a substantial number of establishments, neither sales nor capital were available in the Business Register. Columns (5) and (6) of table 12.4 report results for this most-inclusive sample using specifications similar to columns (2) and (4), respectively. The results are quite congruent with those of the previous columns. We note, however, that in the wider sample, the apparent correlation between sales and $\Gamma(4)$ found earlier is not statistically significant.

\subsubsection{The Probability of Firm Closure}

While equation (8) focuses on the likelihood of displacement, much of the interest in the literature has been on the likelihood of firm or plant closure. We model this outcome using the probit equation:

$$
\operatorname{Pr}\left(D_{j}=1 \mid Y_{j}, D W_{j}\right)=\Phi\left(\beta_{y} Y_{j}+\beta_{D W} D W_{j}\right)
$$

where $D_{j}$ is equal to one if firm $j$ exited the market (economy) between 1993 and 1997, and the other vectors are defined as above. Table 12.5 reports results comparable to the previous literature, with $\beta_{D W}=0$, while table 12.7 introduces the displacement indicator into the equation.

The specifications in columns (1) through (6) mirror those in table 12.3, except for the change in the dependent variable. Neither the capital stock/ 


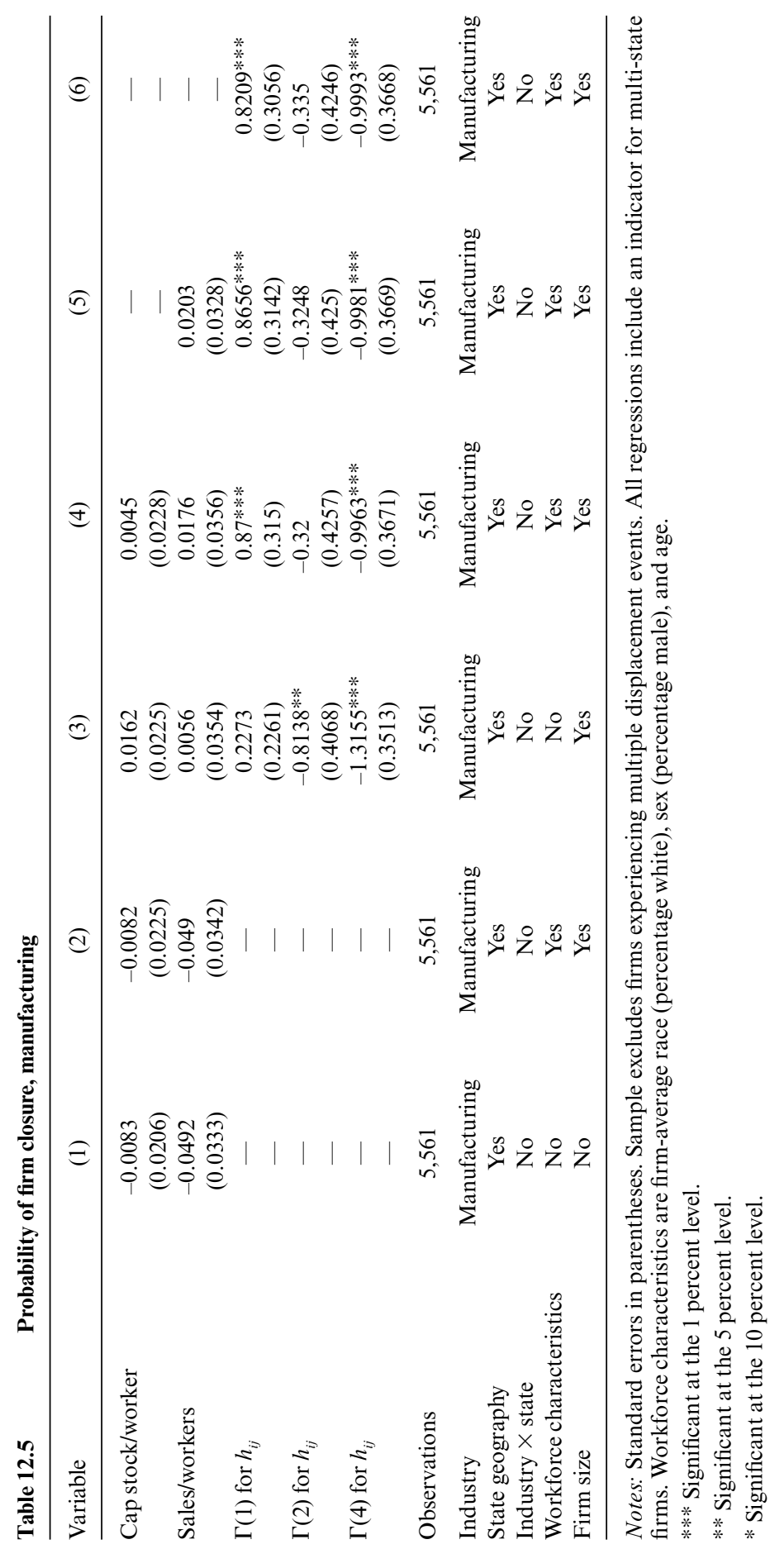


worker nor sales/worker has a statistically significant impact on the probability of closure; however, the magnitude and sign of both effects is comparable to that found in table 12.3, except for capital stock/worker in column (1). Introducing observable workforce characteristics has no effect, by itself, on the estimated impact of sales and assets (compare column [2] to column [1]). The introduction of the human capital distribution into the equation shows that having a workforce heavily concentrated in the first quartile (lower tail) of the distribution is associated with a very strong increase in the probability of firm closure. This effect is magnified, not attenuated, when the workforce characteristics are introduced (compare column [4] to column [3]). In contrast with the displacement equation, not only does the lower tail of the distribution matter for firm closure outcomes, but so does the upper tail-having a workforce heavily concentrated in the fourth quartile of the human capital distribution is associated with a strong decrease in the probability of closure. The magnitude of this effect is slightly attenuated by the introduction of workforce characteristics. A firm with an above-average fraction of its workforce in the upper skill distribution, or a below-average fraction of its workforce in the lower tail, has a significantly lower likelihood of exiting the market in the next five years. Entering the human capital distribution into the equation changes the estimated impact of the capital stock/worker ratio from positive to negative, although the estimated effect is still statistically insignificant. These results are robust to the elimination of the assets variable (see column [5]) and both the asset and sales variables together (see column [6]) - there is no significant change in the estimated parameters. Table 12.6 shows that when estimating the specification in columns (5) and (6) from table 12.5 on the larger sample, the estimated parameters on $\Gamma(1)$ and now $\Gamma(4)$, while still highly significant, are substantially reduced in magnitude. The sales/ worker variable now has a substantial and significant impact on the likelihood of firm death.

Introducing the displacement event indicator, $D W_{j}$, into the firm closure probit equation has no substantive effect on our interpretation of the results. The results are presented in table 12.7 and table 12.8. The displacement indicator is strongly statistically significant in all specifications and samples-not surprising given the raw statistics in table 12.2. The positive regression effect of the displacement event on the probability of firm closure is robust to the inclusion of detailed observable characteristics of the workforce, a full set of industry, geography, and firm structure indicators, and the three skill distribution variables. For the manufacturing firms shown in table 12.7, the effect of having a workforce in the lowest quartile of the human capital distribution is strongly attenuated in comparison to the results not conditioned on the displacement event (compare the same columns in table 12.7 and table 12.5), suggesting that most of the effect of lower skill workers on firm closure operates through increasing the 


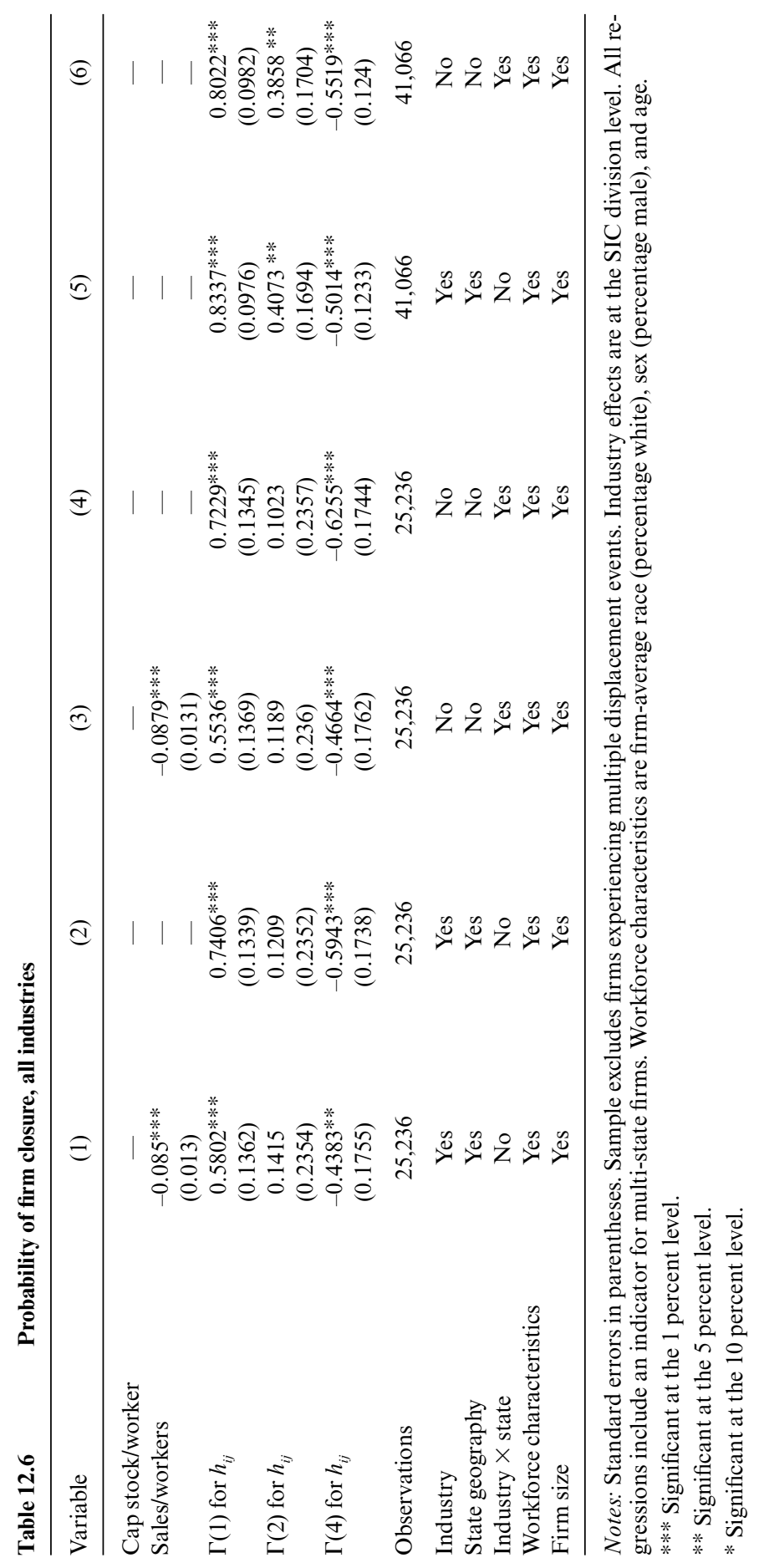




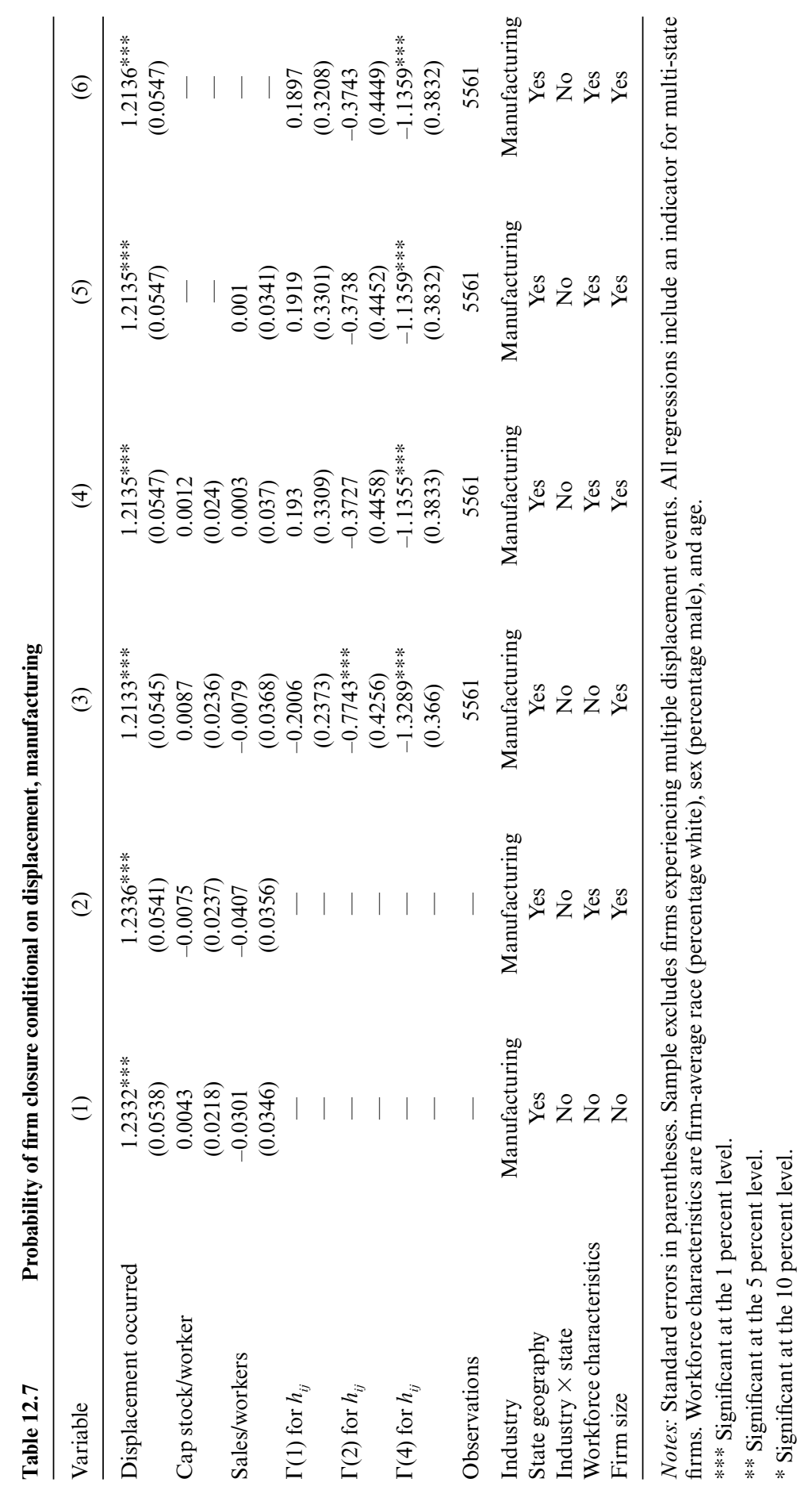




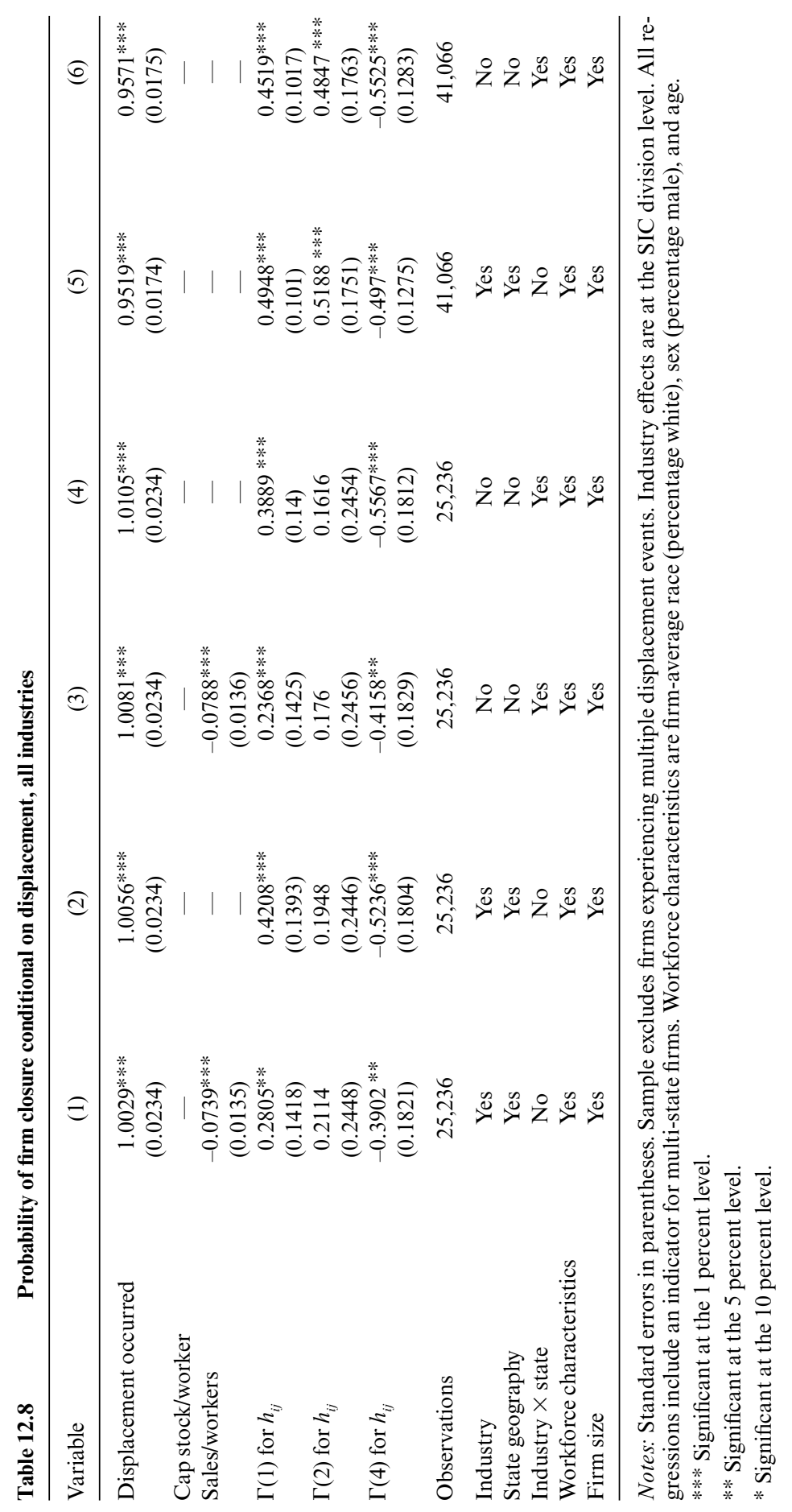


probability of a displacement event. For both manufacturing and all industries, on the other hand, the reduction in the probability of firm closure associated with having a workforce concentrated in the fourth quartile of the human capital distribution is statistically significant and of the same magnitude whether or not the equation controls for the displacement event.

\subsubsection{Changes in the Distribution of Human Capital of Survivors}

In the previous section, we compared employers with and without displacement events, and employers who exited with continuers. In this section, we consider only the continuing employers - those who were active in 1992 and 1997. We compare continuing firms with no displacement events to those with a single displacement event and those with multiple displacement events. We compare how the human capital distribution has changed within continuing employers-contrasting those with one displacement event and those with multiple displacement events to those with no displacement events. The dependent variable is specified as $\Delta \Gamma(k)=$ $\Gamma_{1997}(k)-\Gamma_{1992}(k)$. The regression controls include industry, workforce demographics, state effects, and multi-unit effects. We focus on the results for the first and fourth quartiles (i.e., $k=1,4$, the lowest and highest tails of the distribution).

Table 12.9 reports results from reduced-form regressions of $\Delta \Gamma(k), k=$ 1,4 on a set of indicators representing single and multiple displacement events. Continuing firms reduced their employment of workers in the lowest quartile of the human capital distribution, as indicated by the negative intercept in the $\Delta \Gamma(1)$ equation. Continuing firms increase their employment of workers in the highest quartile of the human capital distribution, as indicated by the positive intercept in the $\Delta \Gamma(4)$ equation. Both of these results are robust to the inclusion of the full set of controls in the equations. These results are also consistent with other studies that have used these human capital components to study how the the distribution of skill within employer and between employers has changed Abowd, Lengermann, and McKinney (2002).

Continuing firms that experienced multiple displacement events are not statistically different from continuers that experienced no displacement events once all controls have been entered into the equations. Continuers with a single displacement event are also not statistically different from other continuers with regard to the change in their employment of the lowest quartile in the skill distribution once all controls are entered. However, continuer firms that experienced a single displacement event increased their employment of the highest quartile of human capital by substantially less than other continuers. This result is robust to the set of controls entered into the equation. A conclusion consistent with this analysis is that a single displacement event is associated with a significant reduction in the upskilling of the continuing firm's workforce. 


\begin{tabular}{|c|c|c|c|c|c|}
\hline $\begin{array}{l}\text { Dependent } \\
\text { variable }\end{array}$ & Variable & $\begin{array}{l}\text { Parameter } \\
\text { estimate }\end{array}$ & $\begin{array}{l}\text { Standard } \\
\text { error }\end{array}$ & $\mathrm{t}$ value & $\operatorname{Pr}>|t|$ \\
\hline \multirow[t]{18}{*}{$\Delta \Gamma(1)$} & Intercept & -0.02664 & 0.00044287 & -60.15 & $<.0001$ \\
\hline & Single displacement & -0.00171 & 0.00144 & -1.19 & 0.2360 \\
\hline & Multi displacement & -0.00311 & 0.00129 & -2.41 & 0.0158 \\
\hline & Controls for SIC & & No & & \\
\hline & Controls for demo & & No & & \\
\hline & Other controls & & No & & \\
\hline & Intercept & -0.03244 & 0.00077698 & -41.75 & $<.0001$ \\
\hline & Single displacement & -0.00367 & 0.00144 & -2.55 & 0.0107 \\
\hline & Multi displacement & -0.00642 & 0.00133 & -4.82 & $<.0001$ \\
\hline & Controls for SIC & & Yes & & \\
\hline & Controls for demo & & No & & \\
\hline & Other controls & & No & & \\
\hline & Intercept & -0.07421 & 0.00221 & -33.65 & $<.0001$ \\
\hline & Single displacement & -0.00132 & 0.00143 & -0.92 & 0.3555 \\
\hline & Multi displacement & -0.00136 & 0.00133 & -1.02 & 0.3055 \\
\hline & Controls for SIC & & Yes & & \\
\hline & Controls for demo & & Yes & & \\
\hline & Other controls & & Yes & & \\
\hline \multirow[t]{18}{*}{$\Delta \Gamma(4)$} & Intercept & 0.00963 & 0.00062011 & 15.53 & $<.0001$ \\
\hline & Single displacement & -0.02014 & 0.00202 & -9.98 & $<.0001$ \\
\hline & Multi displacement & -0.00712 & 0.00180 & -3.95 & $<.0001$ \\
\hline & Controls for SIC & & & No & \\
\hline & Controls for demo & & & No & \\
\hline & Other controls & & & No & \\
\hline & Intercept & 0.02379 & 0.00109 & 21.87 & $<.0001$ \\
\hline & Single displacement & -0.01674 & 0.00201 & -8.32 & $<.0001$ \\
\hline & Multi displacement & 0.00086058 & 0.00187 & 0.46 & 0.6448 \\
\hline & Controls for SIC & & Yes & & \\
\hline & Controls for demo & & No & & \\
\hline & Other controls & & No & & \\
\hline & Intercept & 0.03489 & 0.00311 & 11.22 & $<.0001$ \\
\hline & Single displacement & -0.01420 & 0.00201 & -7.06 & $<.0001$ \\
\hline & Multi displacement & 0.00118 & 0.00188 & 0.63 & 0.53029 \\
\hline & Controls for SIC & & Yes & & \\
\hline & Controls for demo & & Yes & & \\
\hline & Other controls & & Yes & & \\
\hline
\end{tabular}

Notes: All regressions weighted by the number of employees with $6<h<14$. Demographic controls are the fraction of white workers and fraction of male workers. "Other controls" include state effects, indicators for multi-state and multi-unit firms and for firm size. $\mathrm{N}=39418$.

\subsection{Conclusion}

Our analysis can be summarized as follows. Single displacement events occur substantially more often in firms that disproportionately employ workers in the lowest quartile of the human capital distribution. This relation holds in manufacturing and in all industries, whether or not we control for capital/worker or sales/worker, and regardless of the other controls 
in the equation. Firm closures occur substantially more often in firms that disproportionately employ workers in the lowest quartile of the human capital distribution and disproportionately less often in firms that disproportionately employ workers in the highest quartile of this distribution. These relations hold in manufacturing and in all industries, whether or not we control for capital/worker or sales/worker, and are robust to most changes in the control variables. Once we condition the firm closure analysis on the displacement event, our analysis suggests that firms that disproportionately employ workers in the highest quartile of the skill distribution are less likely to close, even given a displacement event, than are other firms that experience displacement events. In this analysis, however, there does not seem to be an effect of disproportionately employing those in the lowest quartile - suggesting that the effect of employing workers who come disproportionately from the lowest part of the human capital distribution on firm closure works through increasing the probability of a displacement event.

Firm or plant survival obviously depends on more variables than the ones included in the analyses presented in this chapter. The age of the firm (Dunne, Klimek, and Roberts 2003; Dunne and Roberts 1990; Freeman and Kleiner 1999), market share and measures of cost (Dunne and Roberts 1990), industry characteristics such as Herfindahl indices or import penetration rates (Freeman and Kleiner 1999), and unionization rates (Abowd 1989; Carneiro and Portugal 2003; Freeman and Kleiner 1999) all appear to matter and have not been included in our analysis. The effect of previous displacement events on the probability of another displacement event also should be studied further. Some, but not all of these issues, can be addressed by incorporating data from the 2002 Economic Census.

\section{Appendix}

\section{Characterization of Firms with Multiple Displacement Events}

By our definition, a multiple displacement firm has more than one displacement event during the 16 quarter period beginning in 1993 quarter 1 and ending in 1996 quarter 4. In addition to the multiple displacement events, these firms differ along other dimensions from single displacers; they have a low exit rate (similar to no displacement firms), use relatively low skill workers, and are disproportionately represented in agriculture, retail, and the service sector. This evidence suggests these firms may be responding (not unexpectedly perhaps, given the low exit rate) to cyclical demand factors, an idea we explore further by looking for a high incidence of annual cyclical displacements. Of course other patterns are present in the 
data, but this approach captures important economic events such as the December holiday season and the seasonal harvesting of agriculture products.

More formally, let $t=1, \ldots, T$ represent the 16 quarterly time periods in our data. The event space of firm displacement patterns is represented by $\omega$ where $a_{t}=0$ when no displacement has occurred and $a_{t}=1$ when a displacement has taken place.

$$
\omega=\left\{\left(a_{1}, \ldots, a_{T}\right): a_{t}=0,1\right\}
$$

Since the firms have multiple displacement events, not all patterns are present in the data. We must also define $S=\Sigma a_{t}$, the sum of all displacement events during the period, which we condition upon in the multiple displacement event space below.

$$
\omega=\left\{\left(a_{1}, \ldots, a_{T}\right): a_{t}=0,1 \mid S=\sum a_{t}>1\right\}
$$

Our approach involves counting the number of annual cyclical patterns

(A3) $C=\sum_{t=5}^{16} I\left(\left[\left\{a_{t-4}, \ldots, a_{t}\right\}=10001\right]+\left[\left\{a_{t-4}, \ldots, a_{t-1}\right\}=1001\right]\right)$

within each firm's $T$-tuple pattern of displacements $w_{j}$. Given the short time period over which we observe the firms, $C$ ranges from a minimum of zero to a maximum of four. In tables $12 \mathrm{~A} .1$ and $12 \mathrm{~A} .2$, we compare the observed $C$ for the 7,389 multiple displacement firms with simulated data, where the simulation assumes random generation of displacements without any seasonality.

Conceptually the simulation is simple; a string of zeros and ones is created for each simulated firm by randomly drawing 16 values from a uniform $[0,1]$ distribution with the values equal to or below cons $=.262$ becoming a one (displacement) and those above a zero. The value cons $=.262$

Table 12A.1 Observed seasonal patterns of multiple displacement firms

\begin{tabular}{lcccccc}
\hline & \multicolumn{5}{c}{ Frequency of seasonal patterns } & \\
\cline { 2 - 6 } Number of displacements & 0 & 1 & 2 & 3 & 4 & Total \\
\hline 2 & 1,382 & 736 & 0 & 0 & 0 & 2,118 \\
& 65.25 & 34.75 & 0.00 & 0.00 & 0.00 & \\
3 & 498 & 592 & 341 & 0 & 0 & 1,431 \\
4 & 34.80 & 41.37 & 23.83 & 0.00 & 0.00 & \\
& 224 & 332 & 257 & 394 & 0 & 1,207 \\
5 and more & 18.56 & 27.51 & 21.29 & 32.64 & 0.00 & \\
& 453 & 840 & 827 & 507 & 6 & 2,633 \\
Total & 17.20 & 31.90 & 31.41 & 19.26 & 0.23 & \\
& 2,557 & 2,500 & 1,425 & 901 & 6 & 7,389 \\
& 34.61 & 33.83 & 19.29 & 12.19 & 0.08 & 100.00 \\
\hline
\end{tabular}


Table 12A.2 Simulated seasonal patterns of multiple displacement firms

\begin{tabular}{lcccccc}
\hline & \multicolumn{5}{c}{ Frequency of seasonal patterns } \\
\cline { 2 - 6 } Number of displacements & 0 & 1 & 2 & 3 & 4 & Total \\
\hline 2 & 79.97 & 20.03 & 0.00 & 0.00 & 0.00 & \\
3 & 56.75 & 37.15 & 6.10 & 0.00 & 0.00 & \\
4 & 39.93 & 42.27 & 15.59 & 2.22 & 0.00 & \\
$5+$ more & 26.10 & 40.72 & 24.95 & 7.60 & 0.63 & \\
Total & 44.07 & 37.31 & 14.88 & 3.50 & 0.25 & 100.00 \\
\hline
\end{tabular}

is determined from the real data by $E\left[a=1 \mid S=\Sigma a_{t}>1\right]$, where the expectation is taken over the entire 16 quarter period. This method insures that the overall proportion of displacement events is the same in both samples, but depending on the data generating process underlying the real data, the distribution of the $T$-tuple patterns may differ substantially.

Interestingly, the real multiple displacers look quite a bit different than the simulated multiple displacers, both in terms of the pattern of total displacements and the frequency of seasonal displacement events. For example, although there is a higher proportion of firms in the real data with two displacement events, there are also more firms with large numbers of displacements $(7+)$, thus ensuring that the average number of displacements per firm is the same as the simulated data (by design). The strong annual cyclical nature of the actual data relative to the simulation can be clearly seen by comparing the frequency of seasonal patterns within each row across tables 12A.1 and 12A.2. For example, if we look at firms with three displacement events, almost 24 percent of the firms in the real data have two seasonal patterns, while only a little over six percent have the same pattern in the simulated data. This evidence suggests that seasonal economic factors play an important role in determining the entry to and the likely structure of the multiple displacement category.

We also explored whether the frequency of seasonal patterns varied substantially across industry. In general, except for agriculture where the frequency of seasonal patterns was exceptionally strong, the pattern of seasonality looked surprisingly similar across industries. Multiple displacers in manufacturing, for example, tend to have a similar frequency of annual seasonal patterns as do multiple displacers in retail, services, and so forth.

\section{References}

Abowd, J. M. 1989. The effect of wage bargains on the stock market value of the firm. American Economic Review 79:774-800. 
Abowd, J. M., P. Corbel, and F. Kramarz. 1999. The entry and exit of workers and the growth of employment: An analysis of French establishments. Review of Economics and Statistics 81 (2): 170-87.

Abowd, J. M., R. H. Creecy, and F. Kramarz. 2002. Computing person and firm effects using linked longitudinal employer-employee data. Technical Paper TP2002-06, Longitudinal Employer-Household Dynamics (LEHD), U.S. Census Bureau.

Abowd, J. M., and F. Kramarz. 1999. Econometric analysis of linked employeremployee data. Labour Economics 6 (1): 53-74.

Abowd, J. M., F. Kramarz, and D. Margolis. 1999. High wage workers and high wage firms. Econometrica 67 (2): 251-333.

Abowd, J. M., P. A. Lengermann, and K. L. McKinney. 2002. The measurement of human capital in the U.S. economy. Technical Paper TP-2002-09, Longitudinal Employer-Household Dynamics (LEHD), U.S. Census Bureau.

Abowd, J. M., and L. Vilhubert. 2005. The sensitivity of economic statistics to coding errors in personal identifiers. Journal of Business and Economic Statistics 23 (2): $133-52$.

Anderson, P. and B. Meyer. 1994. The extent and consequences of job turnover. Brookings Papers on Economic Activity, Microeconomics: 177-248.

Audretsch, D. B. 1994. Business survival and the decision to exit. Journal of the Economics of Business 1 (1): 125-37.

Benedetto, G., J. Haltiwanger, J. Lane, and K. McKinney. 2007. Using worker flows in the analysis of the firm. Journal of Business and Economic Statistics 25 (3): 299-313.

Bernard, A. B., and J. B. Jensen. 2002. The deaths of manufacturing plants. NBER Working Paper no. 9026. Cambridge, MA: National Bureau of Economic Research, May.

Bowlus, A., and L. Vilhuber. 2002. Displaced workers, early leavers, and reemployment wages. Technical Paper TP-2002-18, Longitudinal EmployerHousehold Dynamics (LEHD), U.S. Census Bureau.

Carneiro, A., and P. Portugal. 2003. Wages and the risk of displacement. Working Paper WP 10-03, Banco de Portugal.

Davis, J. A., G. Savage, and R. T. Stewart. 2003. Organizational downsizing: A review of literature for planning and research. Journal of Healthcare Management 48 (3): 181-99.

Davis, S. J., J. C. Haltiwanger, and S. Schuh. 1996. Job creation and destruction. Cambridge, MA: MIT Press.

Dunne, T., S. D. Klimek, and M. J. Roberts. 2003. Entrant experience and plant exit. NBER Working Paper no. 10133. Cambridge, MA: National Bureau of Economic Research, November.

Dunne, T., and M. Roberts. 1990. Wages and the risk of plant closings. Discussion Paper 90-6, CES, U.S. Bureau of the Census, Center for Economic Studies, Washington, D. C.

Dunne, T., M. J. Roberts, and L. Samuelson. 1988. Patterns of firm entry and exit in U.S. Manufacturing Industries. The RAND Journal of Economics 19 (4): 495-515.

Fallick, B. C. 1996. A review of the recent empirical literature on displaced workers. Industrial and Labor Relations Review 50 (1): 5-16.

Foster, L., J. Haltiwanger, and C. J. Krizan. 1998. Aggregate productivity growth: Lessons from microeconomic evidence. NBER Working Paper no. 6803. Cambridge, MA: National Bureau of Economic Research, October.

- 2002. The link between aggregate and micro productivity growth: Evidence from retail trade. NBER Working Paper no. 9120. National Bureau of Economic Research, July. 
Freeman, R. B., and M. M. Kleiner. 1999. Do unions make enterprises insolvent? Industrial and Labor Relations Review 52 (4): 510-27.

Gibbons, R., L. F. Katz, T. Lemieux, and D. Parent. 2005. Comparative advantage, learning, and sectoral wage determination. Journal of Labor Economics 23 (4): 681-724.

Grossman, N. 2002. Shrinking the workforce in an economic slowdown. Compensation and Benefits Management 18 (2): 12-23.

Haltiwanger, J. C., J. I. Lane, and J. R. Spletzer. 2007. Wages, productivity, and the dynamic interaction of businesses and workers. Labour Economics 14 (3): 575-602.

Jacobson, L., R. LaLonde, and D. Sullivan. 1993a. The costs of worker dislocation. Kalamazoo, MI: W. E. Upjohn Institute.

. 1993b. Earnings losses of displaced workers. American Economic Review 83 (4): 685-709.

Kletzer, L. G. 1998. Job displacement. Journal of Economic Perspectives 12 (1): 11536.

Kuhn, P., and A. Sweetman. 1998. Unemployment insurance and quits in Canada. Canadian Journal of Economics 31 (3): 549-72.

Lengermann, P. A., and L. Vilhuber. 2002. Abandoning the sinking ship: The composition of worker flows prior to displacement. Technical Paper TP-2002-11, Longitudinal Employer-Household Dynamics (LEHD), U.S. Census Bureau.

Lluis, S. 2005. The role of comparative advantage and learning in wage dynamics and intrafirm mobility: Evidence from Germany. Journal of Labor Economics 23 (4): 725-69.

McGuckin, R. H., and S. V. Nguyen. 1995. On productivity and plant ownership change: New evidence from the LRD. The RAND Journal of Economics 26 (2): 257-76.

. 2001. The impact of ownership changes: a view from labor markets. International Journal of Industrial Organization 19 (5): 739-62.

Ruhm, C. J. 1994. Advance notice, job search, and postdisplacement earnings. Journal of Labor Economics 12 (1): 1-28.

Schoeni, R. F., and M. Dardia. 1996. Wage losses of displaced workers in the 1990s. Labor and Population Program Working Paper 96-14, RAND Corporation.

Stephens, Jr., M. 2002. Worker displacement and the added worker effect. Journal of Labor Economics 20 (3): 504-37.

Vilhuber, L. Forthcoming. Adjusting imperfect data: Overview and case studies. In Wage structure, raises, and mobility: International comparisons of the structure of wages within and across firms, NBER, ed. E. Lazear and K. Shaw. Chicago: University of Chicago Press. 